\title{
Managed Care, Insurance and Health Care Delivery
}

\section{Managed Care Market Share and Primary Treatment for Cancer}

\author{
Nancy L. Keating, Mary Beth Landrum, Ellen Meara, \\ Patricia A. Ganz, and Edward Guadagnoli
}

Objective. Increases in the market share of managed care are associated with decreases in expenditures in the fee-for-service sector. To understand utilization patterns responsible for such savings, we assessed whether increases in managed care market share were related to increases in receipt of equally effective but less costly primary cancer therapies.

Data Sources. Cancer registry data linked to Medicare administrative data for a population-based sample of fee-for-service Medicare beneficiaries 66 years and older who were diagnosed with breast or prostate cancer during 1993-1999.

Study Design. We used fixed-effects regression models to assess whether county-level increases in the market share of managed care were associated with differences in receipt of cancer therapies that are similar in effectiveness but vary in cost.

Principal Findings. Increases in the market share of managed care were not associated with differences in the receipt of mastectomy versus breast-conserving surgery with radiation for women with early stage breast cancer $(p=.47)$ or with the receipt of conservative therapy (versus surgery or radiation therapy) for men with local or regional prostate cancer $(p=.30)$.

Conclusions. Increases in the market share of managed care do not appear to influence the receipt of equally effective primary treatments for cancer in the fee-for-service sector.

Key Words. Managed care, breast cancer, prostate cancer, treatment choice

Evidence suggests that as the market share of managed care in an area increases, expenditures in Medicare's fee-for-service sector decrease (Baker 1997, 1999; Rodgers and Smith 1999). The ability of managed care to influence spending patterns for patients who are not enrolled in managed care is often called a "spillover effect" and suggests that managed care has induced broad, system-level changes in the delivery of care. However, the changes in utilization responsible for these spillover effects remain poorly understood. 
Because Medicare's prices are set centrally, decreases in expenditures must be a result of decreases in utilization of services. If use of necessary services decreases in areas with higher managed care market share, quality may decline. If, however, fewer unnecessary or inappropriate services are provided, then quality may not change or may improve. Another possibility is that the growth of managed care has prompted greater use of less costly treatments when such treatments are felt to be equally effective or when uncertainty exists about the best treatment. In this case, clinical outcomes are not expected to change, but managed care could affect patient welfare by distorting treatment decisions that might otherwise be driven primarily by patients' preferences.

In this research brief, we used longitudinal data to assess whether increases in the market share of managed care were associated with cancer treatments for Medicare patients in the fee-for-service sector. We focused on primary treatment for early stage breast cancer, for which most women have a choice of equally effective treatments (mastectomy and breast-conserving surgery with radiation) (National Institutes of Health 1990, 1991), and early prostate cancer, for which radical prostatectomy, radiation therapy, and conservative therapy are believed to have equivalent outcomes for most elderly men (Albertsen et al. 1995; Johansson et al. 1997; Holmberg et al. 2002), but where there is uncertainty about the best therapy (Wilt 2000, 2002). For both diseases, trade-offs based on cosmetic outcomes or adverse effects make patients' preferences important. We hypothesized that increases in the market share of managed care in a local area would be associated with greater use of mastectomy, which is less expensive than breast-conserving surgery with radiation (Munoz et al. 1986; Scanlon 1991; Desch et al. 1999), and increases in conservative management of prostate cancer, which is less expensive than radical prostatectomy or radiation therapy (Lu-Yao and Yao 1997; Mettlin et al. 1997).

Address correspondence to Nancy L. Keating, M.D., M.P.H., Department of Health Care Policy, Harvard Medical School, 180 Longwood Avenue, Boston, MA 02115. Dr. Keating is also with the Division of General Internal Medicine, Brigham and Women's Hospital, Boston, MA. Mary Beth Landrum, Ph.D., Ellen Meara, Ph.D., and Edward Guadagnoli, Ph.D., are with the Department of Health Care Policy, Harvard Medical School, Boston, MA. Ellen Meara, Ph.D., is also with the National Bureau of Economic Research, Cambridge MA. Patricia A. Ganz, M.D., is with the Schools of Medicine and Public Health, and Jonsson Cancer Center, University of California, Los Angeles, CA. 


\section{Methods}

\section{Data}

We used the Surveillance, Epidemiology, and End Results (SEER)-Medicare data for this analysis (Potosky et al. 1993). The SEER program of the National Cancer Institute collects uniformly reported data from 11 population-based cancer registries covering approximately 14 percent of the United States population (Ries et al. 2000). For each incident cancer, the SEER registries collect information on month and year of diagnosis, cancer site, tumor characteristics, and patient demographic characteristics, including county of residence. The registries also collect information on treatments (surgery and radiation).

Since 1991, the SEER data have been merged with Medicare administrative data by a matching algorithm that has successfully linked files for more than 94 percent of SEER registry patients diagnosed at age 65 years or older (Potosky et al. 1993). The Medicare claims data used in this study included inpatient claims, claims for physicians' services and other medical services, and claims for outpatient facility services.

\section{Study Cohorts}

We selected patients with a first diagnosis of stage I or II breast cancer or local or regional prostate cancer during 1993-1999, who were at least 66 years old at the time of their cancer diagnosis and continuously enrolled in Parts A and B of fee-for-service Medicare from 1 year before diagnosis through 6 months after diagnosis. We excluded patients with tumor histology suggesting a primary cancer other than that of interest and patients whose month of diagnosis was unknown. We also excluded patients with no claims from 45 days prior to diagnosis through 195 days after diagnosis because we considered their claims incomplete. In the breast cancer cohort, we excluded patients who did not receive definitive primary therapy (breast-conserving surgery with radiation or mastectomy) to directly compare use of these two equally effective treatments. The final samples included 31,063 patients with breast cancer and 58,563 patients with prostate cancer.

\section{Equally Effective Treatments}

We assessed whether breast cancer patients underwent breast-conserving surgery with radiation therapy or mastectomy and whether prostate cancer patients underwent radical prostatectomy, radiation therapy, or conservative therapy (neither radical prostatectomy nor radiation therapy within 6 months 
of diagnosis). Two sources of information about each treatment were available. The SEER registries report data on surgery and radiation delivered or planned within 4 months of diagnosis and the Medicare claims document reimbursed procedures. Studies assessing surgical treatments have found close agreement between the two sources (Cooper et al. 2002), and our findings were similar. In cases where the two sources disagreed $(<3$ percent), we selected the most definitive procedure. We identified radiation therapy if we found evidence for radiation in either source, thus providing more complete ascertainment than either source alone (Du, Freeman, and Goodwin 1999).

\section{Managed Care Market Share}

As described previously (Keating et al. 2005), we defined county-level managed care market share as the number of Medicare beneficiaries enrolled in all managed care contract plans in a county divided by the number of Medicare-entitled beneficiaries in the county using 1993-1999 data from the Centers for Medicare and Medicaid Services. We categorized managed care market share for each patient as $<1,1-10,>10-30$, and $>30$ percent, (Baker and Wheeler 1998; Baker and Brown 1999; Litaker and Cebul 2003; Keating et al. 2005) reflecting approximate quartiles for the patients in the sample over the study period. Patients in our sample resided in 204 counties within 11 SEER regions with a good deal of change in managed care market share during 1993-1999 (Keating et al. 2005). Overall, 119 counties changed from one category to another during the 7-year period, and each registry had counties with changes except for Hawaii (four counties) and Los Angeles (one county). Thus, Hawaii and Los Angeles do not contribute information to the analysis.

Studies of managed care spillover effects have used varying definitions of a health care market (primarily county and metropolitan statistical area [MSA]) and various measures of managed care (Medicare managed care enrollment or total managed care enrollment in a market). We defined markets as the county of residence, allowing us to capture the significant variation in managed care penetration within larger MSAs and increasing the precision of our estimates, as patients in our registries lived in only 30 MSAs. Moreover, using county-level markets allows us to include patients who did not live in an MSA (approximately 42 percent of our sample), increasing the generalizability of our findings. We focused on Medicare managed care penetration because measures of county-level overall managed care penetration are not publicly available prior to 1998 and because Medicare managed care 
penetration is highly correlated with overall managed care penetration at the county level (correlation $=0.64)$ (Baker 1997).

\section{Control Variables}

We obtained information about age, race, Hispanic ethnicity, marital status, year of diagnosis, tumor stage, tumor grade, tumor size, and history of previous cancer from the SEER Registry data. We categorized these variables as in Table 1. We used 1990 Census data for information on education and income by the census tract of residence; patients were assigned to quartiles within each registry to account for regional differences in median income and rates of high school graduation. To measure comorbid illnesses before diagnosis, we calculated diagnostic cost groups (DCGs) (Ellis et al. 1996; Keating et al. 2005), using the Medicare all-encounter model, Release 6.1. DCGs are a claims-based measure of illness originally developed for predicting cost. They capture 118 conditions and are highly predictive of mortality for patients with myocardial infarction (Ash et al. 2003). We used the relative risk score, categorized into quartiles, to summarize morbidity burden.

\section{Analyses}

We estimated the effect of increases in managed care market share on receipt of mastectomy versus breast-conserving surgery with radiation for patients with breast cancer using logistic regression, and on receipt of conservative therapy versus radical prostatectomy versus radiation therapy for patients with prostate cancer using multinomial logistic regression. For each model, the patient was the unit of analysis, allowing adjustment for individual-level characteristics. We also included county of residence in all models, allowing these fixed effects to account for time-invariant differences across counties that could be associated with both managed care market share and the dependent variables (Localio et al. 2001). For each model, the independent variables of interest were the binary variables designating the category of managed care market share for the patient in the county of residence at the time of diagnosis. We adjusted all standard errors for correlation of outcomes within SEER registry.

To aid in interpretation of each model's results, we calculated the adjusted proportion of patients in each of the four categories of managed care market share who received the treatments of interest. Because our data were longitudinal and each model included a fixed county effect, the differences between the proportion receiving a treatment at one level of managed care 
Table 1: Sociodemographic and Clinical Characteristics of the Sample*

\begin{tabular}{|c|c|c|c|c|c|}
\hline \multirow[b]{2}{*}{ Variable } & \multirow[b]{2}{*}{ Value } & \multicolumn{2}{|c|}{ Breast Cancer } & \multicolumn{2}{|c|}{ Prostate Cancer } \\
\hline & & $N$ & $\%$ & $N$ & $\%$ \\
\hline \multirow[t]{5}{*}{ Age } & $66-69$ & 6,534 & 21 & 14,388 & 25 \\
\hline & $70-74$ & 9,232 & 30 & 19,817 & 34 \\
\hline & $75-79$ & 7,805 & 25 & 14,199 & 24 \\
\hline & $80-84$ & 4,918 & 16 & 6,993 & 12 \\
\hline & $\geq 85$ & 2,574 & 8 & 3,166 & 5 \\
\hline \multirow[t]{4}{*}{ Race } & White & 28,306 & 91 & 50,151 & 86 \\
\hline & Black & 1,537 & 5 & 5,156 & 9 \\
\hline & Other & 1,129 & 4 & 2,433 & 4 \\
\hline & Unknown & 91 & $<1$ & 823 & 1 \\
\hline \multirow[t]{3}{*}{ Hispanic ethnicity } & No & 30,003 & 97 & 55,268 & 94 \\
\hline & Yes & 927 & 3 & 2,387 & 4 \\
\hline & Unknown & 133 & $<1$ & 908 & 2 \\
\hline Marital status & Married & 13,849 & 45 & 42,323 & 72 \\
\hline Prior cancer & Prior other cancer & 2,473 & 8 & 5,150 & 9 \\
\hline \multirow{2}{*}{$\begin{array}{l}\text { Modified AJCC* } \\
\text { stage }\end{array}$} & Stage 1 & 18,747 & 60 & - & - \\
\hline & Stage 2 & 12,316 & 40 & - & - \\
\hline \multirow[t]{5}{*}{ Grade } & Well differentiated & 5,555 & 18 & 7,593 & 13 \\
\hline & $\begin{array}{l}\text { Moderately } \\
\text { differentiated }\end{array}$ & 12,102 & 39 & 36,369 & 62 \\
\hline & Poorly differentiated & 7,713 & 25 & 11,433 & 20 \\
\hline & Undifferentiated & 609 & 2 & 243 & $<1$ \\
\hline & Unknown & 5,084 & 16 & 2,925 & 5 \\
\hline \multirow{6}{*}{$\begin{array}{l}\text { Breast cancer tumor } \\
\text { size }\end{array}$} & $\leq 10$ & 9,215 & 30 & - & - \\
\hline & $11-15$ & 7,448 & 24 & - & - \\
\hline & $16-20$ & 5,281 & 17 & - & - \\
\hline & $21-30$ & 5,628 & 18 & - & - \\
\hline & $>30$ & 3,229 & 10 & - & - \\
\hline & Unknown & 262 & 1 & - & - \\
\hline \multirow[t]{7}{*}{ Year of diagnosis } & 1993 & 4,552 & 15 & 10,159 & 17 \\
\hline & 1994 & 4,435 & 14 & 8,752 & 15 \\
\hline & 1995 & 4,524 & 15 & 8,084 & 14 \\
\hline & 1996 & 4,321 & 14 & 7,866 & 13 \\
\hline & 1997 & 4,446 & 14 & 8,112 & 14 \\
\hline & 1998 & 4,397 & 14 & 7,649 & 13 \\
\hline & 1999 & 4,388 & 14 & 7,941 & 14 \\
\hline $\begin{array}{l}\text { Median household } \\
\text { income for census } \\
\text { tract of residence }\end{array}$ & Mean (SD) & 30,553 & $\begin{array}{l}\$ 39,220 \\
(18,262)\end{array}$ & 57,316 & $\begin{array}{l}\$ 39,261 \\
(19,097)\end{array}$ \\
\hline $\begin{array}{l}\text { Proportion of } \\
\text { nonhigh school } \\
\text { graduates in the } \\
\text { census tract of } \\
\text { residence }^{\dagger}\end{array}$ & Mean (SD) & 30,553 & $19.1(11.9)$ & 57,316 & $19.8(12.8)$ \\
\hline Comorbidity score & Mean (SD) & 31,063 & $0.75(1.28)$ & 58,563 & $\begin{array}{r}0.77(1.32) \\
\text { continued }\end{array}$ \\
\hline
\end{tabular}


Table 1: Continued

\begin{tabular}{|c|c|c|c|c|c|}
\hline \multirow[b]{2}{*}{ Variable } & \multirow[b]{2}{*}{ Value } & \multicolumn{2}{|c|}{ Breast Cancer } & \multicolumn{2}{|c|}{ Prostate Cancer } \\
\hline & & $N$ & $\%$ & $N$ & $\%$ \\
\hline \multirow{4}{*}{$\begin{array}{l}\text { Market share of } \\
\text { managed care }(\%)^{\ddagger}\end{array}$} & $<1$ & 6,833 & 22 & 13,275 & 23 \\
\hline & $1-10$ & 9,326 & 30 & 19,389 & 33 \\
\hline & $>10-30$ & 6,560 & 21 & 12,078 & 21 \\
\hline & $>30$ & 8,344 & 27 & 13,821 & 24 \\
\hline
\end{tabular}

*AJCC, American Joint Committee on Cancer. AJCC stage was not available for men with prostate cancer because many men did not undergo complete staging evaluations.

${ }^{\dagger}$ Data on Census tract variables were missing for $1.6 \%$ of breast cancer patients and $2.1 \%$ of prostate cancer patients. For models, patients were assigned to quartiles for the census-level variables within registry to account for regional differences in median income and education levels, and quartiles were then grouped across registries.

${ }^{\ddagger}$ Patients were assigned to a category of managed care market share based on the category of managed care market share for the county where they resided in the year they were diagnosed.

market share and that at another level effectively estimates the impact of changes in the market share of managed care within counties, all else constant. For example, these percentage point changes reflect the difference in the probability of receiving the treatment of interest for two patients with identical characteristics living in the same county if the market share of managed care in the county was to change from one category to another. By assigning patients to one of four different categories of managed care market share rather than using a single continuous variable, the models also allow for effects that differ with the baseline rate of managed care market share in a county.

Because decisions about prostate cancer treatment are often driven by a patient's age and comorbid illness, we tested whether area differences in rates of prostate-specific antigen (PSA) screening might influence treatments. For example, areas with higher rates of PSA screening may identify more relatively sicker and older men with prostate cancer, and such men may be less well suited for radical prostatectomy. We used data from the 5 percent Medicare file to calculate county-level rates of PSA testing in noncancer patients, and we assessed whether these rates were associated with managed care market share. We then included the county-level rate of PSA testing in the model assessing the association between managed care market share and treatment to see if it influenced the association.

Descriptive analyses were conducted using $S A S$ statistical software, version 8.2 (SAS Institute, Cary, NC, USA). Multivariable analyses were conducted using Stata software, version 8 (StataCorp LP, College Station, TX, 
USA). All $p$-values are two sided. The study was approved by the Institutional Review Boards at Harvard Medical School and the University of California at Los Angeles.

\section{RESULTS}

Characteristics of the cohorts of patients meeting the general inclusion criteria for each cancer are included in Table 1. In brief, the mean age of the breast cancer cohort was 75 years, 91 percent were white, 5 percent were black, and 45 percent were married. The mean age of the prostate cancer cohort was 74 years, 86 percent were white, 9 percent were black, and 72 percent were married.

As demonstrated in Table 2, increases in managed care market share were not associated with changes in the proportion of breast cancer patients undergoing mastectomy (versus breast-conserving surgery) with rates approximately $56-58$ percent $(p=.47)$. For patients with prostate cancer, although rates of radical prostatectomy decreased slightly and rates of radiation therapy increased slightly with increasing levels of managed care market share

Table 2: Association between Managed Care Market Share and Rates of Treatment*

\begin{tabular}{llllll}
\hline & \multicolumn{5}{c}{ Category of Managed Care Market } \\
& \multicolumn{5}{c}{ Share (\%) } \\
\cline { 2 - 5 } & $<1$ & $1-10$ & $10-30$ & $>30$ & p-value \\
\cline { 2 - 5 } Indicator & 56.0 & 57.8 & 56.5 & 58.1 & $.47^{\dagger}$ \\
\hline $\begin{array}{l}\text { Breast cancer } \\
\quad \text { Mastectomy (versus breast-conserving } \\
\quad \text { surgery with radiation) (\%) }\end{array}$ & & & & & \\
$\begin{array}{l}\text { Prostate cancer }(N=48,391) \\
\quad \text { Radical prostatectomy (\%) } \\
\quad \text { Radiation (\%) }\end{array}$ & 21.9 & 21.9 & 20.8 & 18.9 & $.30^{\ddagger}$ \\
$\quad$ Conservative treatment (\%) & 35.9 & 35.7 & 37.8 & 40.7 & \\
\hline
\end{tabular}

*Using fixed-effect models, adjusting for patient age, race, ethnicity, marital status, tumor grade, tumor size (breast cancer), tumor stage, year of diagnosis, proportion of high school graduates in the area of residence, median household income of the area of residence, and comorbid illness; models account for clustering at the level of the registry. The differences between the proportion receiving a treatment at one level of managed care market share and that at another level of managed care market share effectively estimates the impact of changes in the market share of managed care within counties, all else constant. Treatments are defined as those received during the first 6 months after diagnosis.

'Using a fixed-effects logistic regression model.

${ }^{\ddagger}$ Using a fixed-effects multinomial logit model. 
in an area, these small differences were not statistically different $(p=.30)$. Rates of conservative therapy (watchful waiting) did not change with area levels of managed care market share.

In noncancer patients, rates of PSA testing varied somewhat by category of managed care market share. The proportion of elderly men without cancer who had a PSA test in the past year was 32.7, 33.6, 31.5, and 34.1 percent for counties with managed care market share $<1,1-10,>10-30,>30$ percent, respectively $(p=.048)$. However, including the county-level rate of PSA in the treatment models did not change the predicted rates of surgery, radiation, or watchful waiting by the various categories of managed care market share.

\section{DISCUSSION}

In a large cohort of elderly patients with early stage breast or prostate cancer, we found no evidence that increases in managed care market share in an area were associated with patterns of primary treatment, despite the availability of equivalent treatments for each cancer with costs that varied substantially. It appears that greater use of less expensive, but equally effective, treatments does not explain the decreased expenditures in areas with greater managed care activity. Moreover, increasing levels of managed care in a market do not appear to be influencing the decision-making process for primary cancer treatment.

Our finding of no association between breast cancer treatments and managed care market share is similar to that of a prior study (Baker and McClellan 2001), although our prostate cancer findings are in contrast. Baker and McClellan found that areas with higher rates of managed care market share had higher rates of prostatectomy and lower rates of radiation. There may be several explanations for this difference. First, we used registry data to examine a cohort of incident cancer patients and assess receipt of treatment (or no treatment) rather than using procedure codes for radiation and surgery in Medicare data to identify incident cases of prostate cancer, which had a sensitivity of 74 percent and a specificity of 76 percent for identifying incident prostate cancers and did not capture patients treated conservatively (Baker and McClellan 2001), and we had richer clinical data about patients and their tumors. Second, we studied care in 1993-1999 versus 1992-1994. Third, our longitudinal data allowed us to examine the effects of changes in managed care market share as opposed to the cross-sectional analysis, which, despite including baseline treatment rates, cannot control for time-invariant unobserved 
confounders as effectively. Finally, we used measures of Medicare managed care market share at the county level as opposed to overall managed care market share at the MSA level.

Other studies have sought to understand changes in care responsible for spillover effects of increases in managed care market share, examining utilization and quality indicators for various conditions. Data suggest that, for Medicare patients hospitalized with acute myocardial infarction, rates of revascularization and cardiac catheterization are somewhat lower in areas with high managed care market share (Heidenreich et al. 2002; Bundorf et al. 2004; Meara et al. 2004), particularly when such care is uncertain or inappropriate (Meara et al. 2004). Moreover, use of effective medications for patients with myocardial infarction is higher in areas with more managed care activity (Heidenreich et al. 2002). Managed care market share is also associated with higher rates of breast and cervical cancer screening (Baker et al. 2004) and colorectal cancer screening (Koroukian et al. 2005) for fee-for-service patients. Other data from one state suggest that high managed care market share is associated with fewer preventable hospitalizations (Backus et al. 2002). Finally, for cancer care, which is often provided across inpatient and outpatient settings, we demonstrated that increases in managed care market share have limited or no effect on the quality of cancer care delivered (Keating et al. 2005). Thus, although the patterns of health care utilization responsible for managed care spillover effects are not yet fully understood, the available evidence does not support negative effects on patient care, at least for important illness such as acute myocardial infarction and cancer. Examining care for other conditions or other phases of illness, such as routine management of chronic disease, care at the end of life (which is resource intensive), or care for which patients' preferences have a less important role, may improve our understanding of managed care's impact in a market.

Our findings should be interpreted in light of some limitations. First, we studied elderly patients living in regions of the country with SEER registries. The elderly population residing in the SEER areas is similar to the general U.S. population in terms of age and sex; however, the SEER population has a higher proportion of nonwhite persons, urban residents, and Medicare health maintenance organizations enrollees than the general U.S. population (Nattinger, McAuliffe, and Schapira 1997; Warren et al. 2002). Nevertheless, this population-based sample includes cancer patients from areas representing 14 percent of the U.S. population. Second, although our use of longitudinal data is a major strength of our study because it allows us to account for time-invariant unobserved effects, such longitudinal data are subject to dynamic selection 
effects. For example, if managed care organizations tend to enroll relatively younger and healthier patients, as the managed care market share increases, the health status of patients in that area's fee-for-service sector may become relatively worse. However, if such dynamic selection influenced our findings, we would expect higher rates of conservative therapy in areas with the highest market share of managed care (where patients in the fee-for-service sector might have poorer health status), and we did not see this effect.

Third, we used fixed-effects logistic regression models for our analyses. Although conditional logistic regression models are theoretically superior, this approach was not computationally feasible given the large number of patients in many counties. Nevertheless, the fixed-effect models are likely to overestimate effects, so with our lack of significant associations, this is of little concern. Fourth, we may have been underpowered to detect very small differences in treatment rates associated with changes in managed care market share, but such differences are unlikely to be clinically meaningful and would not change our overall conclusion that changes in managed care market share do not seem to explain differences in these equally effective therapies. Moreover, the trend we observed was for less conservative management with increasing managed care market share, rather than for more, as we hypothesized. Finally, our measure of managed care was based on Medicare managed care market share, rather than overall managed care market share, because county-level measures of overall managed care were not available during the years of our study. Although these two measures are highly correlated, the overall managed care market share may be better suited for examining spillover effects of managed care because the theory supporting spillover effects considers provider behavior change influenced by all experience with managed care.

\section{CONCLUSIONS}

Increases in the market share of managed care do not appear to influence receipt of equally effective but cost varying primary cancer treatments in the fee-for-service sector. These findings suggest that patient and provider choice is more important than cost in determining therapy. Our findings and those from other studies provide reassurance that cost savings associated with increases in the market share of managed care are not affecting patient welfare by distorting treatment decisions or negatively impacting quality. Further 
studies are needed to fully understand utilization and treatment patterns responsible for savings associated with increases in managed care market share.

\section{ACKNOWLEDGMENTS}

This work was funded by grant CA 0092588 from the National Cancer Institute. Dr. Keating's effort was also funded in part by a Clinical Scientist Development Award from the Doris Duke Charitable Foundation. The authors would like to thank Yang Xu, M.S., and Edward Rosen, M.S., for expert programming assistance.

The authors have no potential conflicts of interest to disclose. This study used the linked SEER-Medicare database. The interpretation and reporting of these data are the sole responsibility of the authors. The authors acknowledge the efforts of the Applied Research Program, NCI; the Office of Research, Development and Information, CMS; Information Management Services (IMS) Inc.; and the Surveillance, Epidemiology, and End Results (SEER) Program tumor registries in the creation of the SEER-Medicare database.

\section{REFERENCES}

Albertsen, P. C., D. G. Fryback, B. E. Storer, T. F. Kolon, and J. Fine. 1995. "LongTerm Survival among Men with Conservatively Treated Localized Prostate Cancer." Journal of the American Medical Association 274 (8): 626-31.

Ash, A. S., M. A. Posner, J. Speckman, S. Franco, A. C. Yacht, and L. Bramwell. 2003. "Using Claims Data to Examine Mortality Trends Following Hospitalization for Heart Attack in Medicare." Health Services Research 38 (5): 1253-62.

Backus, L., M. Moron, P. Bacchetti, L. C. Baker, and A. B. Bindman. 2002. "Effect of Managed Care on Preventable Hospitalization Rates in California." Medical Care 40 (4): 315-24.

Baker, L. C. 1997. "The Effect of HMOs on Fee-for-Service Health Care Expenditures: Evidence from Medicare." Journal of Health Economics 16 (4): 453-81.

— 1999. "Association of Managed Care Market Share and Health Expenditures for Fee-for-Service Medicare Patients." Journal of the American Medical Association $281(5): 432-7$.

Baker, L. C., and M. L. Brown. 1999. "Managed Care, Consolidation among Health Care Providers, and Health Care: Evidence from Mammography." RAND Journal of Economics 30: 351-74.

Baker, L. C., and M. B. McClellan. 2001. "Managed Care, Health Care Quality, and Regulation.” Journal of Legal Studies XXX: 715-41. 
Baker, L. C., K. A. Phillips, J. S. Haas, S. Y. Liang, and D. Sonneborn. 2004. “The Effect of Area HMO Market Share on Cancer Screening." Health Services Research 39 (6, part 1): 1751-72.

Baker, L. C., and S. K. Wheeler. 1998. "Managed Care and Technology Diffusion: The Case of MRI." Health Affairs (Millwood) 17 (5): 195-207.

Bundorf, M. K., K. A. Schulman, J. A. Stafford, D. Gaskin, J. G. Jollis, and J. J. Escarce. 2004. "Impact of Managed Care on the Treatment, Costs, and Outcomes of Feefor-Service Medicare Patients with Acute Myocardial Infarction.” Health Services Research 39 (1): 131-52.

Cooper, G. S., B. Virnig, C. N. Klabunde, N. Schussler, J. Freeman, and J. L. Warren. 2002. "Use of SEER-Medicare Data for Measuring Cancer Surgery." Medical Care 40 (8 suppl): IV-43-8.

Desch, C. E., L. T. Penberthy, B. E. Hillner, M. K. McDonald, T. J. Smith, A. L. Pozez, and S. M. Retchin. 1999. "A Sociodemographic and Economic Comparison of Breast Reconstruction, Mastectomy, and Conservative Surgery.” Surgery 125 (4): 441-7.

Du, X., J. L. Freeman, and J. S. Goodwin. 1999. "Information on Radiation Treatment in Patients with Breast Cancer: The Advantages of the Linked Medicare and SEER Data." Journal of Clinical Epidemiology 52 (5): 463-70.

Ellis, R. P., G. C. Pope, L. I. Iezzoni, J. Z. Ayanian, D. W. Bates, H. Burstin, and A. S. Ash. 1996. "Diagnosis-Based Risk Adjustment for Medicare Capitation Payments." Health Care Financing Review 17 (3): 101-28.

Heidenreich, P. A., M. McClellan, C. Frances, and L. C. Baker. 2002. "The Relation between Managed Care Market Share and the Treatment of Elderly Fee-forService Patients with Myocardial Infarction.” American Journal of Medicine 112 (3): 176-82.

Holmberg, L., A. Bill-Axelson, F. Helgesen, J. O. Salo, P. Folmerz, M. Haggman, S. O. Andersson, A. Spangberg, C. Busch, S. Nordling, J. Palmgren, H. O. Adami, J. E. Johansson, and B. J. Norlen. 2002. "A Randomized Trial Comparing Radical Prostatectomy with Watchful Waiting in Early Prostate Cancer." New England Journal of Medicine 347 (11): 781-9.

Johansson, J. E., L. Holmberg, S. Johansson, R. Bergstrom, and H. O. Adami. 1997. "Fifteen-Year Survival in Prostate Cancer." Journal of the American Medical Association 277 (6): 467-71.

Keating, N. L., M. B. Landrum, E. Meara, P. A. Ganz, and E. Guadagnoli. 2005. "Do Increases in Managed Care Market Share of Managed Care Influence Quality of Cancer Care in the Fee-for-Service Sector?" Journal of the National Cancer Institute 97: 257-64.

Koroukian, S. M., D. Litaker, A. Dor, and G. S. Cooper. 2005. "Use of Preventive Services by Medicare Fee-for-Service Beneficiaries: Does Spillover from Managed Care Matter?” Medical Care 43 (5): 445-52.

Litaker, D., and R. D. Cebul. 2003. "Managed Care Penetration, Insurance Status, and Access to Health Care." Medical Care 41 (9): 1086-95.

Localio, A. R., J. A. Berlin, T. R. Ten Have, and S. E. Kimmel. 2001. "Adjustments for Center in Multicenter Studies: An Overview." Annals of Internal Medicine 135 (2): $112-23$. 
Lu-Yao, G. L., and S. L. Yao. 1997. "Population-Based Study of Long-Term Survival in Patients with Clinically Localised Prostate Cancer." Lancet 349 (9056): 906-10.

Meara, E., M. B. Landrum, J. Z. Ayanian, B. J. McNeil, and E. Guadagnoli. 2004. "The Effect of Market Share of Managed Care on Appropriate Use of Coronary Angiography among Traditional Medicare Beneficiaries." Inquiry 41 (2): 144-58.

Mettlin, C. J., G. P. Murphy, M. P. Cunningham, and H. R. Menck. 1997. "The National Cancer Data Base Report on Race, Age, and Region Variations in Prostate Cancer Treatment." Cancer 80 (7): 1261-6.

Munoz, E., F. Shamash, M. Friedman, I. Teicher, and L. Wise. 1986. "Lumpectomy vs Mastectomy. The Costs of Breast Preservation for Cancer.” Archives of Surgery 121 (11): 1297-301.

National Institutes of Health. 1990. Treatment of Early Stage Breast Cancer. Consensus Development Conference Statement. Bethesda, MD: National Institutes of Health.

National Institutes of Health. 1991. "Treatment of Early-Stage Breast Cancer." Journal of the American Medical Association 265: 391-95.

Nattinger, A. B., T. L. McAuliffe, and M. M. Schapira. 1997. "Generalizability of the Surveillance, Epidemiology, and End Results Registry Population: Factors Relevant to Epidemiologic and Health Care Research." Journal of Clinical Epidemiology 50 (8): 939-45.

Potosky, A. L., G. F. Riley, J. D. Lubitz, R. M. Mentnech, and L. G. Kessler. 1993. "Potential for Cancer Related Health Services Research Using a Linked Medicare-Tumor Registry Database.” Medical Care 31 (8): 732-48.

Ries, L. A., P. A. Wingo, D. S. Miller, H. L. Howe, H. K. Weir, H. M. Rosenberg, S. W. Vernon, K. Cronin, and B. K. Edwards. 2000. "The Annual Report to the Nation on the Status of Cancer, 1973-1997." Cancer 88 (10): 2398-424.

Rodgers, J., and K. E. Smith. 1999. Do Medicare HMOs Reduce Fee-for-Service Costs? Washington, DC: Price Waterhoulse LLP, Health Policy Economics Group.

Scanlon, E. F. 1991. "The Role of Reconstruction in Breast Cancer." Cancer 68 (5 suppl): 1144-7.

Warren, J. L., C. N. Klabunde, D. Schrag, P. B. Bach, and G. F. Riley. 2002. “Overview of the SEER-Medicare Data: Content, Research Applications, and Generalizability to the United States Elderly Population.” Medical Care 40 (8 suppl): IV-318.

Wilt, T. J. 2000. "Uncertainty in Prostate Cancer Care: The Physician's Role in Clearing the Confusion." Journal of the American Medical Association 283 (24): 3258-60.

—. 2002. "Clarifying Uncertainty Regarding Detection and Treatment of EarlyStage Prostate Cancer.” Seminars in Urologic Oncology 20 (1): 10-7. 